CLINICAL STUDY

\title{
The sex-specific association of serum osteoprotegerin and receptor activator of nuclear factor $\kappa B$ legend with bone mineral density in older adults: the Rancho Bernardo Study
}

\author{
Anna Stern, Gail A Laughlin, Jaclyn Bergstrom and Elizabeth Barrett-Connor \\ Department of Family and Preventive Medicine, School of Medicine, University of California, San Diego, 9500 Gilman Drive, La Jolla, California $92093-$ \\ 0607, USA \\ (Correspondence should be addressed to G A Laughlin; Email: glaughlin@ucsd.edu)
}

\begin{abstract}
Objective: The role of osteoprotegerin (OPG) and its receptor activator of nuclear factor $\kappa \mathrm{B}$ legend (RANKL) in the regulation of bone in humans remain unclear. We examined the sex-specific associations of serum OPG, RANKL, and their ratio with bone mineral density (BMD) in older adults. Design: Participants were 681 community-dwelling adults, ages 45-90 years, who had serum OPG and RANKL measured and bone density scans in 1988-1991, with follow-up scans 5 and/or 10 years later.

Methods: Analyses were sex-specific; women using and not using estrogen were evaluated separately. Cross-sectional analyses used multivariable regression models; longitudinal analyses used repeated measures mixed effects models.

Results: In cross-sectional analyses, age- and weight-adjusted serum OPG levels were significantly positively associated with BMD at the lumbar spine in men, and at the femoral neck, total hip, and lumbar spine in women using estrogen, but not in non-users of estrogen. RANKL concentrations were significantly and inversely associated with BMD in men only, and at the total hip. Neither OPG nor RANKL was significantly associated with bone loss. Results for the RANKL/OPG ratio were the same as those for RANKL alone.

Conclusions: These results suggest a modulatory effect of both endogenous and exogenous sex hormones on the biologic interaction of OPG, RANKL, and bone.

European Journal of Endocrinology 156 555-562
\end{abstract}

\section{Introduction}

The osteoprotegerin/receptor activator of nuclear factor $\kappa \mathrm{B}$ legend/receptor activator of nuclear factor $\kappa \mathrm{B}$ (OPG/RANKL/RANK) system is thought to play a major role in the regulation of osteoclastogenesis and to be the chief mechanism by which osteoblast and osteoclast activity are coupled to coordinate bone formation and bone resorption $(1,2)$. OPG, a soluble receptor secreted by osteoblasts and other cell types, competitively binds RANKL expressed primarily on osteoblasts, preventing RANKL from binding to the RANK on osteoclasts (3).

In vitro studies have shown that in the absence of OPG, RANKL binds to the RANK receptor, promoting the proliferation and differentiation of pre-osteoclasts, and prolonging osteoclast survival by suppressing apoptosis (4-7). In the presence of OPG, osteoclast differentiation, activation, and survival are inhibited (4, 6). Variations in the balance of OPG and RANKL are thought to critically contribute to the pathology of osteoporosis and other bone diseases $(4,6)$.
The effects of alterations in the OPG/RANKL/RANK pathway have been demonstrated in genetic models. In OPG knockout mice, the number of osteoclasts is increased markedly and severe osteoporosis develops throughout the skeleton $(4,8,9)$. Transgenic mice overexpressing OPG produce almost no osteoclasts and develop osteopetrosis $(4,6)$. Mice administered serum RANKL developed elevated levels of osteoclast growth and activation, leading to osteoporosis $(2,7)$. In humans, a mutant gene encoding OPG has been found; the mutant OPG produced by this gene fails to suppress bone resorption, resulting in severe bone deformities (10).

Published findings of serum OPG-bone mineral density (BMD) associations in humans have been inconsistent $(3,11-18)$, and few studies have assessed the associations of RANKL (18-20) and the RANKL/ OPG ratio $(20,21)$ with BMD. To test the a priori hypotheses that OPG-BMD associations are positive and RANKL-BMD associations are negative in humans, we conducted a cross-sectional and prospective study of the associations of serum levels of OPG, RANKL, and their 
ratio with BMD in older men and postmenopausal women, stratified by use of estrogen.

\section{Materials and methods}

\section{Study population}

Between 1988 and 1991, 82\% $(n=2031)$ of surviving community-dwelling men and women from the Rancho Bernardo Study, a study of healthy middle to upper middle class ambulatory older Caucasian adults aged 45-90, participated in a baseline osteoporosis study visit. To be eligible for the present analysis, participants had to have returned for a third osteoporosis visit about 10 years after the baseline osteoporosis visit. Of the original osteoporosis study cohort, 1095 (54\%) died prior to the third osteoporosis visit. Of the remaining 936 participants, 681 (73\%) had sufficient serum stored for analysis of serum OPG and RANKL levels and had one $(n=52)$ or two $(n=617)$ subsequent bone density scans. The surviving participants were younger, consumed alcohol more frequently, and exercised more frequently than those who did not participate. Each visit for this study was approved by the Institutional Review Board of the University of California, San Diego. All participants gave written informed consent.

\section{Measurements}

Baseline age, medical history, and health habits were assessed using standardized questionnaires. Data on current health habits were dichotomized: current cigarette smoking (yes/no); alcohol consumption on three or more days per week (yes/no); exercise on three or more days per week (yes/no); and current estrogen use (yes/no). Smoking, exercise frequency, alcohol frequency, and current estrogen use were self-reported. In this cohort, self-reported lifestyle measures correlate with relevant measurements, such as pulmonary function, pulse rate, high density lipoprotein cholesterol, and liver function tests (22-24). Current estrogen use at baseline was validated by examination of pills and prescriptions brought to the clinic for that purpose.

$\operatorname{BMD}\left(\mathrm{g} / \mathrm{cm}^{2}\right)$ of the femoral neck, total hip, and lumbar spine (L1-L4) was measured using dual-energy X-ray absorptiometry (DXA; Hologic QDR-1000; Hologic, Inc., Bedford, MA, USA). Scans were standardized daily against a calibration phantom. Weight was measured using a balance beam scale with participants wearing light clothing and no shoes.

Serum from non-fasting blood samples obtained by venipuncture on the day of the baseline bone scan was separated and frozen at $-70{ }^{\circ} \mathrm{C}$. OPG and RANKL were measured in 2004 at Amgen, Inc. in Thousand Oaks, CA, USA. Serum OPG levels were measured using an ELISA commercial kit (Biomedica Gruppe, Vienna, Austria) that detects monomeric, dimeric, and ligand bound OPG. The published sensitivity of the assay was $2.8 \mathrm{pg} / \mathrm{ml}$; the intra- and interassay coefficients of variation were $4-10$ and $7-8 \%$ respectively. RANKL levels were assayed using an ELISA (Biomedica Gruppe) that detects soluble, uncomplexed human RANKL in serum. The manufacturer's insert indicates that the ELISA can reliably detect values below $1.6 \mathrm{pg} / \mathrm{ml}$ using extrapolation. For the purposes of this study, values $>$ $0.20 \mathrm{pg} / \mathrm{ml}$ were included in the analyses as measured; levels for 75 individuals ( 27 men and 48 women) with values below $0.20 \mathrm{pg} / \mathrm{ml}$ were set at $0.20 \mathrm{pg} / \mathrm{ml}$ for these analyses. The intra- and interassay coefficients of variation for RANKL were 3-5 and 6-9\% respectively.

Serum samples were stored at $-70{ }^{\circ} \mathrm{C}$ for up to 16 years before assay, and information regarding the effect of long-term storage are limited (25). However, OPG and RANKL data were available for a subset of 139 Rancho Bernardo participants at two different visits 11 years apart, providing samples assayed after 5-16 years of storage. There were no associations between storage duration and OPG or RANKL concentrations in these samples. Also, means and variances for OPG and RANKL concentrations did not differ between the two visits. Serum OPG and RANKL concentrations did not vary significantly with time of the day of blood draw or the number of hours since last dietary intake.

\section{Statistical analysis}

All variables except OPG and RANKL levels were normally distributed. Natural log-transformed OPG and RANKL values approximated normality and were used in all statistical analyses. OPG and RANKL data are presented as either the geometric mean or in standardized units to simplify interpretation. For all analyses, data were stratified into three comparison groups: men $(n=307)$, women using estrogen at the baseline osteoporosis visit $(n=173)$ and women not using estrogen at the baseline visit $(n=201)$. The latter group included 106 prior estrogen users $85 \%$ of whom had stopped estrogen long enough ( $>1$ year) for the protective effect of estrogen therapy on BMD to reverse (26).

Descriptive statistics of the study cohort were summarized using means with 95\% confidence intervals for continuous variables or proportions for dichotomous variables. Least squared means and the ordinary $\chi^{2}$ test were used to evaluate significant differences among the three comparison groups. Student's t-test and the ordinary $\chi^{2}$ were used to compare the characteristics of participants included in these analyses to those in the baseline osteoporosis cohort not included in the present study due to death prior to the third osteoporosis visit, lack of archived sera, or no subsequent bone scan.

Covariates were evaluated for incorporation in the OPG-BMD and RANKL-BMD models by testing individual associations with OPG and RANKL; correlations were used for continuous variables and least squared 
means were used for dichotomous variables. Covariates significantly associated with OPG or RANKL and BMD that changed the coefficient estimate of OPG or RANKL as a predictor of BMD by $>15 \%$ were considered confounding variables.

Multiple linear regression models were used to examine associations between OPG, RANKL, and their ratio with BMD. Models were evaluated unadjusted and by adding one covariate at a time. In adjusted models, regression diagnostics verified that data met normal regression assumptions including linearity, normality of residuals, and lack of collinearity. Additional adjustment for time of day of blood draw and number of hours since last dietary intake did not materially alter results.

Mixed-effects models for repeated measures were used to evaluate associations of baseline OPG and RANKL, with change in BMD between baseline and subsequent visits $\sim 5$ and 10 years later. These models were adjusted for the same covariates used in the multilinear regression models.

All $P$-values were based on two-tailed significance, defined as $P<0.05$. No adjustments were made for multiple comparisons, in order to reduce type 2 errors (27). All statistical analyses were conducted using the SAS system package (version 9.1, SAS Institute, Cary, NC, USA).

\section{Results}

\section{Characteristics of participants}

Table 1 shows the baseline characteristics of the 307 men and 374 women aged 45-90 years who participated in this study. More than 98\% of women were postmenopausal. Men weighed more, had a higher $\mathrm{BMD}$, and reported more frequent alcohol consumption than women. Women not using estrogen had the lowest BMD. OPG and RANKL levels did not differ significantly by sex or by women's estrogen use status.

\section{Associations of OPG and RANKL with osteo- porosis risk factors}

As shown in Fig. 1, increasing age was associated with significantly higher OPG levels $(P<0.001)$ for all three comparison groups. Table 2 summarizes associations of OPG and RANKL with osteoporosis risk factors. For men only, OPG levels were lower for those who reported drinking alcohol three or more days per week compared with those who reported drinking less frequently or not at all (age adjusted geometric mean: $102.5 \mathrm{vs} 118.2 \mathrm{pg} /$ $\mathrm{ml}$ respectively, $P=0.001)$. For women using estrogen, OPG concentrations were higher for smokers compared with those who were past or never smokers (age adjusted geometric mean: 142.4 vs $105.1 \mathrm{pg} / \mathrm{ml}$ respectively, $P=0.012$ ). Weight, $\mathrm{BMI}$, and exercise frequency were not significantly associated with OPG.

RANKL levels did not differ significantly by sex, age, weight, BMI, alcohol use, or exercise frequency among men or women. For men only, RANKL levels were higher for smokers compared with those who were past smokers or never smoked (age adjusted geometric mean: 1.9 vs $0.9 \mathrm{pg} / \mathrm{ml}$ respectively, $P=0.011$ ).

The correlation of RANKL with the RANKL/OPG ratio was $0.93(P<0.001)$ and did not vary among the three study groups. The correlation of OPG with the

Table 1 Baseline characteristics of study participants 1988-1991; Rancho Bernardo, California.

\begin{tabular}{|c|c|c|c|c|}
\hline & $\begin{array}{l}\text { Men }(n=307) \\
\text { mean }(95 \% \mathrm{Cl})\end{array}$ & $\begin{array}{l}\text { Women using ET } \\
(n=173) \\
\text { mean }(95 \% \mathrm{Cl})\end{array}$ & $\begin{array}{c}\text { Nomen not using ET } \\
(n=201) \\
\text { mean }(95 \% \mathrm{Cl})\end{array}$ & $P$ value \\
\hline Age (years) & $69.43(68.53,70.34)$ & $66.45(65.25,67.66)$ & $69.88(68.76,71.00)$ & $<0.001$ \\
\hline Weight $(\mathrm{kg})^{\mathrm{a}}$ & $81.2(80.0,82.5)$ & $62.8(61.2,64.5)$ & $65.4(66.4,66.9)$ & $<0.001$ \\
\hline BMI $\left(\mathrm{kg} / \mathrm{m}^{2}\right)^{\mathrm{a}}$ & $26.43(26.04,25.82)$ & $24.33(23.80,24.86)$ & $25.35(24.88,25.84)$ & $<0.001$ \\
\hline $\mathrm{OPG}(\mathrm{pg} / \mathrm{ml})^{\mathrm{b}}$ & $107.6(101.8,113.7)$ & $114.5(106.8,122.7)$ & $109.2(102.7,116.3)$ & 0.410 \\
\hline RANKL (pg/ml) & $1.8(1.5,1.9)$ & $1.6(1.3,1.9)$ & $1.85(1.56,2.1)$ & 0.542 \\
\hline RANKL/OPG ratio ${ }^{b}$ & $0.014(0.011,0.018)$ & $0.009(0.007,0.010)$ & $0.013(0.010,0.017)$ & 0.092 \\
\hline \multicolumn{5}{|l|}{ BMD } \\
\hline Hip: neck $\left(\mathrm{g} / \mathrm{cm}^{2}\right)^{\mathrm{b}}$ & $0.7452(0.7315,0.7589)$ & $0.7102(0.6900,0.7275)$ & $0.6727(0.6573,0.6881)$ & $<0.001$ \\
\hline Hip: total hip $\left(\mathrm{g} / \mathrm{cm}^{2}\right)^{\mathrm{b}}$ & $0.9408(0.9256,0.9561)$ & $0.8827(0.8635,0.9020)$ & $0.8313(0.8142,0.8585)$ & $<0.001$ \\
\hline \multirow[t]{2}{*}{ Lumbar spine $\left(\mathrm{L} 1-\mathrm{L} 4 ; \mathrm{g} / \mathrm{cm}^{2}\right)^{\mathrm{b}}$} & $1.0276(1.0059,1.0494)$ & $1.0013(0.9739,1.0287)$ & $0.922(0.8975,0.9465)$ & $<0.001$ \\
\hline & $\%$ Yes & $\%$ Yes & $\%$ Yes & \\
\hline Current smoking $^{\mathrm{b}}$ & 7.1 & 9.8 & 7.5 & 0.551 \\
\hline $\begin{array}{l}\text { Current alcohol use on } 3 \text { or more } \\
\text { days per week }\end{array}$ & 59.2 & 52.0 & 42.8 & 0.001 \\
\hline $\begin{array}{l}\text { Current exercise } 3 \text { or more times } \\
\text { per week }^{\mathrm{b}}\end{array}$ & 46.3 & 46.2 & 37.8 & 0.128 \\
\hline
\end{tabular}

$\mathrm{ET}$, estrogen therapy; $\mathrm{Cl}$, confidence interval; BMI, body mass index; OPG, osteoprotegerin; RANKL, receptor activator of nuclear factor $\kappa \mathrm{B}$; BMD, bone mineral density; Data are means $(95 \% \mathrm{Cl})$ for continuous variables and proportions for dichotomous variables; values for OPG, RANKL, and RANKL/OPG are geometric means.

${ }^{a}$ Age adjusted.

${ }^{\mathrm{b}}$ Age and weight adjusted. 


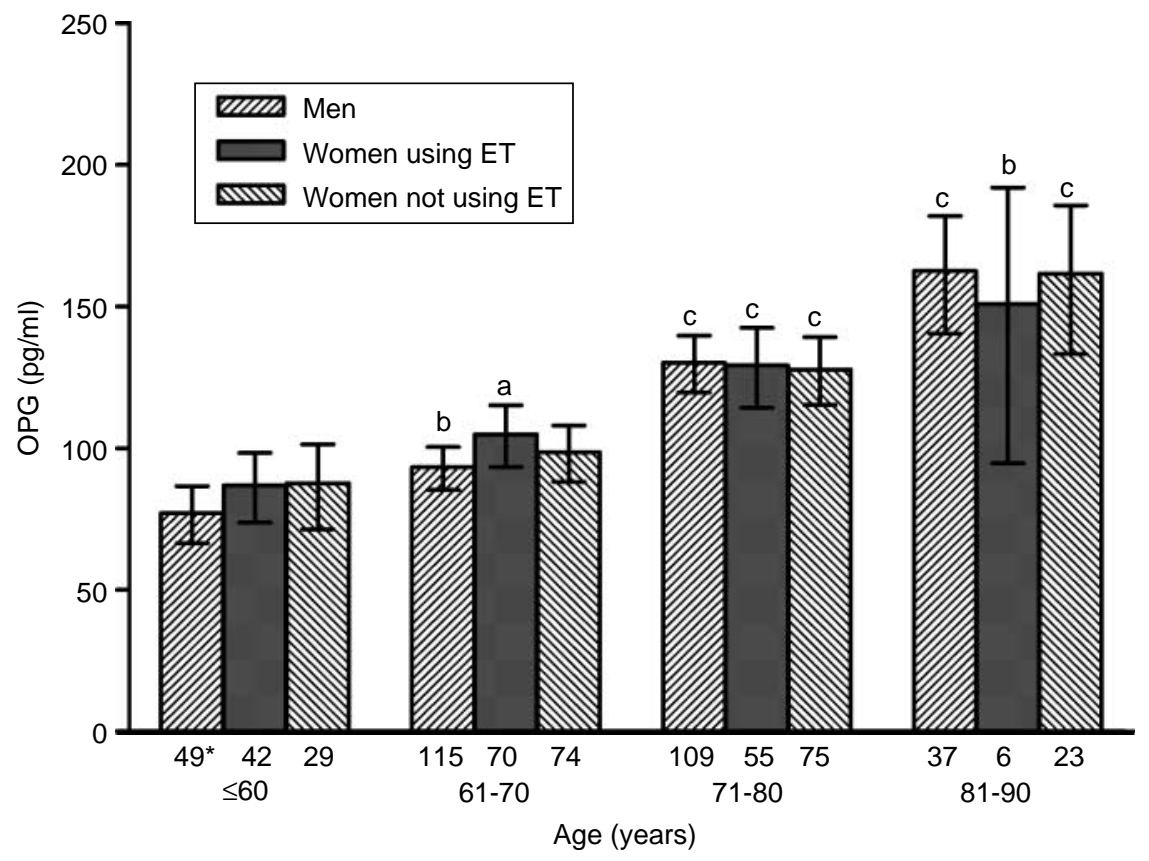

Figure 1 Baseline geometric mean OPG levels by age category for each study group; Rancho Bernardo, California, 1981-1991. Abbreviations: OPG, osteoprotegerin; ET, estrogen therapy. ${ }^{\mathrm{a}} P<$ $0.05,{ }^{b} P<0.01,{ }^{\mathrm{c}} P<0.001$ versus age $\leq 60$ years for the corresponding group; *sample size. ratio was -0.33 for men, -0.47 for women not using estrogen, and -0.36 for women using estrogen (all $P<$ 0.001). There were no significant correlations between serum OPG and RANKL.

\section{Associations of OPG, RANKL, and their ratio with BMD}

Table 3 summarizes results of multilinear regressions of OPG, RANKL, and their ratio with BMD. Higher levels of OPG were associated with higher BMD at the lumbar spine, femoral neck, and total hip for women using estrogen but not non-users. For men, higher OPG levels were associated with higher BMD only at the lumbar spine.

Higher RANKL levels were significantly associated with lower BMD at the total hip in men only; higher RANKL levels were also marginally associated with lower BMD at the femoral neck $(P<0.074)$ and lumbar spine $(P<0.069)$ in men, but only after adjustment for all covariates. No RANKL-BMD associations were observed in women. RANKL/OPG ratio associations with BMD were essentially the same as those for RANKL (data not shown).

\section{Associations of OPG and RANKL with changes in BMD}

The annual percent change in BMD from baseline was significant for all three groups at all three bone sites. Rates of bone loss at the femoral neck and the total hip were not significantly different between men and women not using estrogen, but were significantly lower for women using estrogen $(P<0.001)$. All comparison groups had a net gain in bone at the lumbar spine, consistent with osteoarthritis. Baseline

Table 2 Correlations of serum OPG and RANKL levels with covariates 1988-1991; Rancho Bernardo, California.

\begin{tabular}{|c|c|c|c|c|c|c|}
\hline & \multicolumn{3}{|c|}{ OPG (pg/ml) } & \multicolumn{3}{|c|}{ RANKL (pg/ml) } \\
\hline & Men $(n=307)$ & $\begin{array}{l}\text { Women on } \\
\text { estrogen } \\
(n=173)\end{array}$ & $\begin{array}{l}\text { Women not on } \\
\text { estrogen } \\
(n=201)\end{array}$ & Men $(n=307)$ & $\begin{array}{l}\text { Women on } \\
\text { estrogen } \\
(n=173)\end{array}$ & $\begin{array}{l}\text { Women not on } \\
\text { estrogen } \\
(n=202)\end{array}$ \\
\hline Age (years) & $0.552^{*}$ & $0.309^{*}$ & $0.418^{*}$ & -0.009 & -0.012 & 0.006 \\
\hline Weight (pounds) ${ }^{a}$ & -0.058 & 0.122 & -0.067 & 0.003 & -0.036 & 0.037 \\
\hline $\operatorname{BMI}\left(\mathrm{kg} / \mathrm{m}^{2}\right)^{\mathrm{a}}$ & -0.059 & 0.089 & -0.063 & -0.077 & -0.065 & 0.033 \\
\hline RANKL (geometric mean) ${ }^{\mathrm{b}}$ & 0.024 & -0.010 & -0.136 & 1.000 & 1.000 & 1.000 \\
\hline OPG (geometric mean) ${ }^{\mathrm{b}}$ & 1.000 & 1.000 & 1.000 & 0.024 & -0.010 & -0.136 \\
\hline
\end{tabular}

OPG, osteoprotegerin; RANKL, receptor activator of nuclear factor $\kappa \mathrm{B}$; BMI, body mass index. ${ }^{\star} P<.001$.

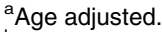

${ }^{\mathrm{b}}$ Age and weight adjusted. 
Table 3A $\beta$ Coefficients for the multiple linear regressions of serum levels of OPG and RANKL with baseline BMD for 307 older men and 274 postmenopausal women, 1998-1991; Rancho Bernardo, California.

\begin{tabular}{|c|c|c|c|c|c|c|c|c|c|}
\hline \multirow[b]{3}{*}{ Models and adjustments: } & \multicolumn{9}{|c|}{ Men $(n=307)$} \\
\hline & \multicolumn{3}{|c|}{ Femoral neck } & \multicolumn{3}{|c|}{ Total hip } & \multicolumn{3}{|c|}{ Lumbar spine } \\
\hline & $\beta$ & SE & $P$ value & $\beta$ & SE & $P$ value & $\beta$ & SE & $P$ value \\
\hline \multicolumn{10}{|l|}{ For 307 older men } \\
\hline Age & 0.007 & 0.009 & 0.393 & -0.020 & 0.010 & 0.859 & 0.020 & 0.014 & 0.149 \\
\hline Age, weight, lifestyle ${ }^{a}$ & 0.012 & 0.008 & 0.135 & 0.005 & 0.010 & 0.549 & 0.033 & 0.013 & 0.012 \\
\hline Age, weight, lifestyle, RANKL & 0.012 & 0.008 & 0.133 & 0.006 & 0.009 & 0.539 & 0.033 & 0.013 & 0.011 \\
\hline \multicolumn{10}{|l|}{ RANKL } \\
\hline Age, weight & 0.010 & 0.007 & 0.119 & -0.017 & 0.007 & 0.020 & -0.016 & 0.011 & 0.130 \\
\hline Age, weight, lifestyle & -0.012 & 0.006 & 0.065 & -0.017 & 0.007 & 0.015 & -0.017 & 0.011 & 0.092 \\
\hline Age, weight, lifestyle, OPG & -0.012 & 0.007 & 0.074 & -0.017 & 0.007 & 0.017 & -0.019 & 0.011 & 0.070 \\
\hline
\end{tabular}

Women using estrogen $(n=173)$

Women not using estrogen $(n=201)$

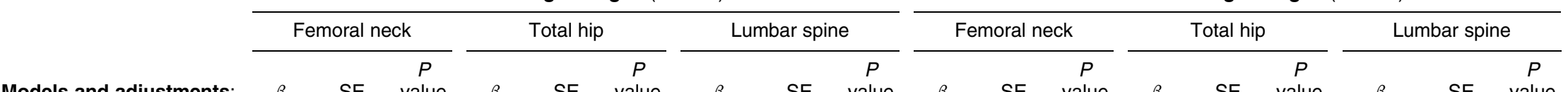

For 274 postmenopausal women

OPG

$\begin{array}{lllllll}\text { Age, weight, lifestyle }^{\mathrm{a}} & 0.016 & 0.008 & 0.045 & 0.018 & 0.009 & 0.044\end{array}$

$\begin{array}{llllll}\text { Age, weight, lifestyle, } \quad 0.015 & 0.008 & 0.047 & 0.018 & 0.009 & 0.045\end{array}$

RANKL

RANKL

Age

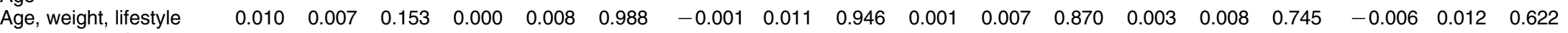
Age, weight, lifestyle,

$\begin{array}{lllllllllllllllllll}0.010 & 0.007 & 0.157 & 0.001 & 0.008 & 0.917 & 0.003 & 0.011 & 0.819 & 0.010 & 0.007 & 0.846 & 0.003 & 0.008 & 0.610 & -0.007 & 0.012 & 0.581\end{array}$ OPG

OPG, osteoprotegerin; RANKL, receptor activator of nuclear factor $\mathrm{KB}$; BMD, bone mineral density; Values are standardized $\beta$ coefficients; OPG and RANKL were log-transformed for analyses.

Lifestyle variables include current smoking (yes/no) and use of alcohol on three or more days per week (yes/no). 
OPG and RANKL levels were not associated with change in BMD at any site for any of the three comparison groups.

\section{Discussion}

In this cohort of older men and women, we found an independent, positive cross-sectional association of OPG with BMD at the lumbar spine, femoral neck, and total hip in women estrogen users, but not in women nonusers of estrogen. In men, multiply adjusted OPG levels were associated with BMD at the lumbar spine only. Higher RANKL levels were significantly associated with higher BMD at the hip in men, but not women. Neither OPG nor RANKL predicted 5 to 10 year change in BMD.

The absence of a positive association of OPG with BMD in women who were not using estrogen is concordant with five of six previous studies $(3,11,14$, $16,21,28)$. Only one prior study explicitly assessed women using estrogen. In that study of 490 postmenopausal women, OPG levels were higher in the 70 women who were using estrogen compared with those who were not, but no significant OPG-BMD associations were found in either group (16). Although OPG concentrations did not differ in estrogen-users versus non-users in our study, significant positive OPG-BMD associations were found at all bone sites for women using estrogen. These results are consistent with animal and in vitro studies showing that higher levels of estrogen are associated with higher levels of OPG $(6,29-31)$ and that OPG inhibits osteoclast activity, resulting in less bone resorption $(5-9,32,33)$.

Three of six previous studies $(3,11,13,15,19,20)$ reported positive OPG-BMD associations in men. In the present study, higher OPG levels were significantly associated with higher BMD at the lumbar spine after adjustment for covariates. No significant associations were observed at the femoral neck or total hip. Endogenous levels of estrogen and testosterone and their effects on OPG may be confounding the associations. In vitro studies have shown that estrogen increases OPG, while testosterone and the non-aromatizable androgen $5 \alpha$-dihydrotestosterone seemingly have the opposite effect $(15,28,29,34,35)$. Alternatively, because of the number of associations evaluated, the OPG-spine BMD association only in men and only at a single bone site may be due to chance.

Although no RANKL-BMD associations were found for women, for men higher RANKL levels were significantly associated with lower BMD at the total hip and marginally associated with lower BMD at the femoral neck and lumbar spine. Two other studies have published RANKL-BMD associations in humans. One reported no association at the middle and distal phalanges in 566 men and women aged 18-75 years (19); the other reported an inverse association at the femoral neck in 80 Korean men aged 42-70 years (20).
The inverse RANKL-BMD association for men in our study is in the predicted direction, given the expected function of RANKL.

An inverse RANKL-BMD association in men but not women raises the question whether testosterone mediates this association. One in vitro study supports this thesis; the androgen dihydrotestosterone (derived from testosterone in human tissues) inhibited OPG mRNA levels and protein secretion by osteoblastic cells by up to $60 \%$ (34). However, testosterone had no effect on RANKL mRNA expression in a study of mouse bone cells (35), and no association between RANKL serum levels and testosterone was found in a study of 289 men (19). Nevertheless, testosterone may indirectly mediate the RANKL-BMD association by acting on other modulators of the RANKL-RANK pathway. Older men have much higher estrogen levels than postmenopausal woman, but estrogen seems unlikely to be an important modulator of the RANKL-BMD association in that no association was observed in women using estrogen, who have circulating levels of estradiol similar to those in older men.

Standard levels of OPG and RANKL are not wellestablished (2). OPG levels reported here are within the wide range published in other studies. Mean values of OPG (for assays that detect all OPG forms) have ranged from 10 to $246 \mathrm{pg} / \mathrm{ml}(3,14-16,21)$, with the exception of one study reporting 1359 and $1229 \mathrm{pg} /$ $\mathrm{ml}$ for pre- and postmenopausal women respectively (28). Wide ranges in reported values likely reflect differences in study populations, collection and storage methods, assay detection levels, and improved detection levels in newer assays (2). Consistent with earlier studies $(3,11-13,15,19,28)$, we found higher serum OPG levels with increasing age, no sex differences in OPG, and no difference in serum RANKL levels by age or sex.

Most RANKL is cell bound and serum levels are low (7). Until recently, RANKL assays were not sensitive enough to detect levels for a large proportion of healthy individuals (21). One study reported that $55 \%$ of postmenopausal women had undetectable levels (21). Mean values using the less sensitive assays ranged from 7 (3) to $26 \mathrm{pg} / \mathrm{ml}(20,21,36,37)$. According to the manufacturer's insert for the Biomedica kit, levels below $1.6 \mathrm{pg} / \mathrm{ml}$ can now be reliably detected. For the present study, the detectable level of RANKL was set at $0.20 \mathrm{pg} /$ $\mathrm{ml}$. By these criteria, only $11 \%$ of the cohort had undetectable levels and the mean value of $1.73 \mathrm{pg} / \mathrm{ml}$ was therefore lower than that reported in other studies.

Baseline OPG and RANKL values were not associated with 5 to 10 year change in BMD at the femoral neck, total hip, or lumbar spine in men or women. In the only other study of OPG and bone loss (11), OPG was not related to 5 year change in femoral neck or total hip BMD in 180 postmenopausal women. There are several reasons why serum OPG and RANKL levels measured at a single point in time may not predict change in BMD 
over time. First, because OPG levels increase with age, baseline values may reflect current bone status but not predict future bone loss. Secondly, while RANKL levels are relatively stable over time, the ability of RANKL to induce the RANK signaling system depends on levels of other modulators such as macrophage colony-stimulating factor, and the levels of these modulators are dynamic over time (2). Finally, some mediation of bone resorption occurs downstream of RANK and therefore is independent of OPG and RANKL levels at any single point in time (4).

This study has several strengths, including the community-dwelling cohort of relatively healthy ambulatory adults unselected for osteoporosis who were not using bone-specific medications at baseline, the prospective design, quality controlled DXA scans, relatively large sample size, inclusion of both sexes, and validated hormone therapy use. Study limitations include the fact that OPG and RANKL are produced by many different cells, thus serum concentrations are not bone-specific $(3,38)$. In addition, circulating OPG and RANKL levels are low, difficult to measure, and may not reflect intracellular concentrations or activity. This might partially explain low or absent associations with BMD, but would not explain different associations by sex. Like all studies of older adults, healthy participant bias and survival bias were present. However, these biases were unlikely to contribute to the estrogen use specific OPGBMD associations in women or to the significant inverse RANKL-BMD association only in men. Previous Rancho Bernardo studies have shown that poor renal function is associated with decreased BMD (39), whereas diabetes is associated with higher BMD (40). Measures of renal function and diabetes are not available at the baseline visit for this study, therefore the effect of the association of these two conditions on OPG and RANKL associations could not be examined. Because of the number of associations evaluated, some associations may be due to chance. Finally, the Rancho Bernardo cohort was comprised almost entirely of white, relatively welleducated, and middle or upper-middle class adults; results may not be generalizable to other ethnic or socioeconomic groups.

In conclusion, the selective association of OPG and BMD in women using estrogen suggests that exogenous estrogen may inhibit osteoclast activity indirectly by increasing OPG levels in the bone microenvironment, and is in line with laboratory studies showing a modulatory effect of estrogens on OPG-bone biology in females. Only men showed a significant RANKL-BMD association. This unexpected result may indicate a testosterone or other sex hormone effect on modulators of the RANKL-BMD system. More studies are needed to confirm these sex differences, to clarify their etiology, and to quantify the importance of OPG and RANKL on the RANK pathway relative to other mediators of osteoclast activity. Whether measurement of circulating levels of these cytokines will be clinically relevant is not yet clear.

\section{Acknowledgements}

This study was funded by a research grant from the National Institutes of Health on Aging: AG07181. The serum OPG and RANKL assays were run by Stephen Adamu and Frank Suncion at Amgen, Inc. Amgen, Inc. paid for and ran the OPG and RANKL assays. Elizabeth Barrett-Connor is a consultant to an Amgen-sponsored registry designed to study patient compliance with bone-specific medications or hormone therapy. Neither of these activities influenced this manuscript and there is no conflict of interest. All other authors have no conflicts of interest.

\section{References}

1 Khosla S. Minireview: the OPG/RANKL/RANK system. Endocrinology 2001142 5050-5055.

2 Rogers A \& Eastell R. Circulating osteoprotegerin and receptor activator for nuclear factor kappaB ligand: clinical utility in metabolic bone disease assessment. Journal of Clinical Endocrinology and Metabolism $2005906323-6331$.

3 Kudlacek S, Schneider B, Woloszczuk W, Pietschmann P \& Willvonseder R. Serum levels of osteoprotegerin increase with age in a healthy adult population. Bone 200332 681-686.

4 Hofbauer LC \& Heufelder AE. Role of receptor activator of nuclear factor-kappaB ligand and osteoprotegerin in bone cell biology. Journal of Molecular Medicine 200179 243-253.

5 Yasuda H, Shima N, Nakagawa N, Yamaguchi K, Kinosaki M, Mochizuki S, Tomoyasu A, Yano K, Goto M, Murakami A, Tsuda E, Morinaga T, Higashio K, Udagawa N, Takahashi N \& Suda T. Osteoclast differentiation factor is a ligand for osteoprotegerin/ osteoclastogenesis-inhibitory factor and is identical to TRANCE/ RANKL. PNAS 199895 3597-3602.

6 Simonet WS, Lacey DL, Dunstan CR, Kelley M, Chang MS, Luthy R, Nguyen HQ, Wooden S, Bennett L, Boone T, Shimamoto G, Derose M, Elliott R, Colombero A, Tan HL, Trail G, Sullivan J, Davy E, Bucay N, Renshaw-Gegg L, Hughes TM, Hill D, Pattison W, Campbell P, Sander S, Van G, Tarpley J, Derby P, Lee R \& Boyle WJ. Osteoprotegerin: a novel secreted protein involved in the regulation of bone density. Cell 199789 309-319.

7 Lacey DL, Timms E, Tan HL, Kelley MJ, Dunstan CR, Burgess T, Elliott R, Colombero A, Elliott G, Scully S, Hsu H, Sullivan J, Hawkins N, Davy E, Capparelli C, Eli A, Qian YX, Kaufman S, Sarosi I, Shalhoub V, Senaldi G, Guo J, Delaney J \& Boyle WJ. Osteoprotegerin ligand is a cytokine that regulates osteoclast differentiation and activation. Cell 199893 165-176.

8 Bucay N, Sarosi I, Dunstan CR, Morony S, Tarpley J, Capparelli C, Scully S, Tan HL, Xu W, Lacey DL, Boyle WJ \& Simonet WS. Osteoprotegerin-deficient mice develop early onset osteoporosis and arterial calcification. Genes and Development 199812 1260-1268.

9 Mizuno A, Amizuka N, Irie K, Murakami A, Fujise N, Kanno T, Sato Y, Nakagawa N, Yasuda H, Mochizuki S, Gomibuchi T, Yano K, Shima N, Washida N, Tsuda E, Morinaga T, Higashio K \& Ozawa H. Severe osteoporosis in mice lacking osteoclastogenesis inhibitory factor/osteoprotegerin. Biochemical and Biophysical Research Communications 1998247 610-615.

10 Cundy T, Hegde M, Naot D, Chong B, King A, Wallace R, Mulley J, Love DR, Seidel J, Fawkner M, Banovic T, Callon KE, Grey AB, Reid IR, Middleton-Hardie CA \& Cornish J. A mutation in the gene 
TNFRSF11B encoding osteoprotegerin causes an idiopathic hyperphosphatasia phenotype. Human Molecular Genetics 2002 $112119-2127$.

11 Indridason OS, Franzson L \& Sigurdsson G. Serum osteoprotegerin and its relationship with bone mineral density and markers of bone turnover. Osteoporosis International $200516417-423$.

12 Yano K, Tsuda E, Washida N, Kobayashi F, Goto M, Harada A, Ikeda K, Higashio K \& Yamada Y. Immunological characterization of circulating osteoprotegerin/osteoclastogenesis inhibitory factor: increased serum concentrations in postmenopausal women with osteoporosis. Journal of Bone and Mineral Research $199914518-$ 527.

13 Szulc P, Hofbauer LC, Heufelder AE, Roth S \& Delmas PD. Osteoprotegerin serum levels in men: correlation with age, estrogen, and testosterone status. Journal of Clinical Endocrinology and Metabolism 200186 3162-3165.

14 Rogers A, Saleh G, Hannon RA, Greenfield D \& Eastell R. Circulating estradiol and osteoprotegerin as determinants of bone turnover and bone density in postmenopausal women. Journal of Clinical Endocrinology and Metabolism 2002874470 4475.

15 Khosla S, Arrighi HM, Melton LJ III, Atkinson EJ, O'fallon WM, Dunstan C \& Riggs BL. Correlates of osteoprotegerin levels in women and men. Osteoporosis International 200213 394-399.

16 Browner WS, Lui LY \& Cummings SR. Associations of serum osteoprotegerin levels with diabetes, stroke, bone density, fractures, and mortality in elderly women. Journal of Clinical Endocrinology and Metabolism 200186 631-637.

17 Schett G, Kiechl S, Redlich K, Oberhollenzer F, Weger S, Egger G, Mayr A, Jocher J, Xu Q, Pietschmann P, Teitelbaum S, Smolen J \& Willeit J. Soluble RANKL and risk of nontraumatic fracture. JAMA 2004291 1108-1113.

18 Abrahamsen B, Hjelmborg JV, Kostenuik P, Stilgren LS, Kyvik K, Adamu S, Brixen K \& Langdahl BL. Circulating amounts of osteoprotegerin and RANK ligand: genetic influence and relationship with BMD assessed in female twins. Bone 200536 727-735.

19 Trofimov S, Pantsulaia I, Kobyliansky E \& Livshits G. Circulating levels of receptor activator of nuclear factor-kappaB ligand/osteoprotegerin/macrophage-colony stimulating factor in a presumably healthy human population. European Journal of Endocrinology $2004150305-311$.

20 Oh KW, Rhee EJ, Lee WY, Kim SW, Baek KH, Kang MI, Yun EJ, Park CY, Ihm SH, Choi MG, Yoo HJ \& Park SW. Circulating osteoprotegerin and receptor activator of NF-kappaB ligand system are associated with bone metabolism in middle-aged males. Clinical Endocrinology 200562 92-98.

21 Mezquita-Raya P, De La Higuera M, Garcia DF, Alonso G, RuizRequena ME, De Dios Luna J, Escobar-Jimenez F \& MunozTorres M. The contribution of serum osteoprotegerin to bone mass and vertebral fractures in postmenopausal women. Osteoporosis International 200516 1368-1374.

22 Frette C, Barrett-Connor E \& Clausen JL. Effect of active and passive smoking on ventilatory function in elderly men and women. American Journal of Epidemiology 1996143 757-765.

23 Reaven PD, Mcphillips JB, Barrett-Connor EL \& Criqui MH. Leisure time exercise and lipid and lipoprotein levels in an older population. Journal of the American Geriatrics Society 199038 847-854.

24 Greendale GA, Barrett-Connor E, Edelstein S, Ingles S \& Haile R. Lifetime leisure exercise and osteoporosis. The Rancho Bernardo study. American Journal of Epidemiology 1995141 951-959.

25 Chan BY, Buckley KA, Durham BH, Gallagher JA \& Fraser WD. Effect of anticoagulants and storage temperature on the stability of receptor activator for nuclear factor-kappa $\mathrm{B}$ ligand and osteoprotegerin in plasma and serum. Clinical Chemistry 2003 49 2083-2085.
26 Gallagher JC, Rapuri PB, Haynatzki G \& Detter JR. Effect of discontinuation of estrogen, calcitriol, and the combination of both on bone density and bone markers. Journal of Clinical Endocrinology and Metabolism 200287 4914-4923.

27 Rothman KJ. No adjustments are needed for multiple comparisons. Epidemiology 19901 43-46.

28 Oh KW, Rhee EJ, Lee WY, Kim SW, Oh ES, Baek KH, Kang MI, Choi MG, Yoo HJ \& Park SW. The relationship between circulating osteoprotegerin levels and bone mineral metabolism in healthy women. Clinical Endocrinology 200461 244-249.

29 Saika M, Inoue D, Kido S \& Matsumoto T. 17beta-estradiol stimulates expression of osteoprotegerin by a mouse stromal cell line, ST-2, via estrogen receptor-alpha. Endocrinology 2001142 2205-2212.

30 Hofbauer LC, Khosla S, Dunstan CR, Lacey DL, Spelsberg TC \& Riggs BL. Estrogen stimulates gene expression and protein production of osteoprotegerin in human osteoblastic cells. Endocrinology 1999140 4367-4370.

31 Michael H, Harkonen PL, Vaananen HK \& Hentunen TA. Estrogen and testosterone use different cellular pathways to inhibit osteoclastogenesis and bone resorption. Journal of Bone and Mineral Research $2005202224-2232$.

32 Tsuda E, Goto M, Mochizuki S, Yano K, Kobayashi F, Morinaga T \& Higashio K. Isolation of a novel cytokine from human fibroblasts that specifically inhibits osteoclastogenesis. Biochemical and Biophysical Research Communications 1997234 137-142.

33 Yasuda H, Shima N, Nakagawa N, Mochizuki SI, Yano K, Fujise N, Sato Y, Goto M, Yamaguchi K, Kuriyama M, Kanno T, Murakami A, Tsuda E, Morinaga T \& Higashio K. Identity of osteoclastogenesis inhibitory factor (OCIF) and osteoprotegerin (OPG): a mechanism by which OPG/OCIF inhibits osteoclastogenesis in vitro. Endocrinology 1998139 1329-1337.

34 Hofbauer LC, Hicok KC, Chen D \& Khosla S. Regulation of osteoprotegerin production by androgens and anti-androgens in human osteoblastic lineage cells. European Journal of Endocrinology $2002147269-273$.

35 Chen Q, Kaji H, Kanatani M, Sugimoto T \& Chihara K. Testosterone increases osteoprotegerin mRNA expression in mouse osteoblast cells. Hormone and Metabolic Research 200436 674-678.

36 Eghbali-Fatourechi G, Khosla S, Sanyal A, Boyle WJ, Lacey DL \& Riggs BL. Role of RANK ligand in mediating increased bone resorption in early postmenopausal women. Journal of Clinical Investigation $2003 \mathbf{1 1 1} 1221-1230$.

37 Hawa G, Brinskelle-Schmal N, Glatz K, Maitzen S \& Woloszczuk W. Immunoassay for soluble RANKL (receptor activator of NF-kappaB ligand) in serum. Clinical Laboratory 200349 461-463.

38 Makhluf HA, Mueller SM, Mizuno S \& Glowacki J. Age-related decline in osteoprotegerin expression by human bone marrow cells cultured in three-dimensional collagen sponges. Biochemical and Biophysical Research Communications 2000268 669-672.

39 Jassal SK, von Muhlen D \& Barrett-Connor E. Measures of renal function, BMD, bone loss, and osteoporotic fracture in older adults: the Rancho Bernardo study. Journal of Bone and Mineral Research 200722 203-210.

40 Barrett-Connor E \& Holbrook TL. Sex differences in osteoporosis in older adults with non-insulin-dependent diabetes mellitus. JAMA $1992163333-3337$.

Received 18 December 2006

Accepted 6 March 2007 